This is a posptrint version of the article:

Maialen Marin-Lacarta \& Mireia Vargas-Urpi (2018): Translators revising translators: a

fruitful alliance, Perspectives, DOI: 10.1080/0907676X.2018.1533569

\title{
Translators revising translators: a fruitful alliance
}

\author{
Maialen Marin-Lacarta ${ }^{\mathrm{i}}$ \\ Mireia Vargas-Urpi ${ }^{\text {ii }}$
}

${ }^{i}$ Translation Programme, Hong Kong Baptist University, Hong Kong, Hong Kong SAR

${ }^{i i}$ Department of Translation and Interpreting, and East Asian Studies, Universitat Autònoma de Barcelona, Barcelona, Spain

This article discusses the revision process in a non-profit digital publisher led by translators and aims to fill the research gap with regard to the revision process in literary translation. ¡Hjckrrh! is a non-profit publishing initiative that has published 21 e-books translated from 7 different languages, with the collaboration of 14 translators. This article discusses the revision process in ¡Hjckrrh! by documenting the making of two e-books. We use multiple sources of data collection: 16 in-depth interviews with participants (translators, revisers, a proofreader, the cover designer); participants' reflective diaries; fieldnotes from our participant observation in the form of reflective diaries; e-mail correspondence between the participants; translation drafts; and drafts of the paratexts. This article describes the workflow and provides an overview of the revision process in ${ }_{i} H j \mathrm{jckrrh}$ !. The article pays special attention to the negotiation of decisions and the interactions between the actors. The conclusions show that translators appreciate a detailed revision and are willing to take part in the final decision making. The detailed documentation of the process shows that the boundaries between the various revision stages are blurred and that the revision of style and language permeates the whole process.

Keywords: revision; digital translations; proofreading; copy-editing; e-books; self-publishing.

\section{Introduction}

Research on the revision of translations is relatively scarce and has mainly focused on 
non-literary texts, as noted in Mossop’s (2007b, 2011-2016) reviews of previous studies. Another aspect that has not been explored to date is the social dimension of revision; that is, how revisers and translators interact (if they eventually do) and how changes are suggested and negotiated.

This article seeks to help fill in these gaps by exploring the revision process in ¡Hjckrrh!, a self-publishing initiative ${ }^{1}$ led by three translators that issues literary translations in e-book format. ${ }^{2}$ This article is part of a larger project entitled Digital Translations in the Making: Hong Kong Contemporary Fiction in Spanish, which examines the making of two e-books by this publishing initiative.

¡Hjckrrh! was created in 2013 by three Spanish literary translators. As of March 2018, ¡Hjckrrh! had published 21 e-books translated from 8 different languages (Turkish, Hungarian, English, Italian, Chinese, German, Catalan and Portuguese), and 14 translators collaborated in the making of these e-books. These translations are essays or short fiction and do not usually exceed 10,000 words. Most of the actors involved in ¡Hjckrrh! are professional translators; there is no formal chief editor, although one of the founding members often assumes this role (Marin-Lacarta and Vargas-Urpi, 2018). It issues translations of literary works that are in the public domain or whose rights have been donated by the authors. Translations published by ¡Hjckrrh! are designed only to be published as e-books. The translations are commercialised at a symbolic price through different platforms for all types of e-reading devices, and the earnings are used to cover the costs of their website hosting. The motivations of the founding members and collaborators to contribute to this non-lucrative initiative will be explored in a forthcoming article.

1 We use the term ‘self-publishing initiative’ because ¡Hjckrrh! is not legally established as a publishing company and translators translate, edit, proofread and upload their own work.

2 More information about ¡Hjckrrh! is available on their website: http://hjckrrh.org/ 
This article uses different sources of data (interviews with translators, revision drafts, e-mail correspondence) to analyse how revision is developed in terms of workflow and social interactions in this particular kind of publishing initiative where translators revise other translators’ work on a non-lucrative basis.

\section{Previous research on revision}

Studies of the revision of translations may explore revisions by the original translator (self-revision), a second translator and a non-translator (unilingual revising) (Mossop, 2011-2016). For this reason, Mossop (2011-2016) suggests a broad definition for this activity: 'Revision is the process of reading a translation to decide whether it is of satisfactory quality, and making any needed changes’. Mossop’s contributions are key to understanding the basic ideas about revisions in translation (2007a) and provide a panoramic view of previous research in this area (2007b, 2011-2016).

The International Standard (ISO 17100:2015) on Requirements for Translation Services provides a more rigid definition of what revision entails. It is considered as part of the translation process and explicitly mentions that ' $[\mathrm{t}] \mathrm{he}$ reviser shall examine the target language content against the source language content for any errors and other issues, and its suitability for purpose’ (ISO 17100:2015, 5.3.3). Furthermore, ISO 17100:2015 states that the reviser, 'who shall be a person other than the translator', shall have the same competences and qualifications as the translator.

Revision studies have often adopted a quantitative approach and focused on nonliterary translation. The relation between revision and quality is an important issue, and some studies have quantified the number of remaining errors after different kinds of revisions (see, for instance, Arthern, 1983; or Brunette, Gagnon and Hine, 2005).

Qualitative methods have also been used; for example, Künzli (2006) recorded revisers’ comments while revising (similar to think-aloud-protocols) and uses them to compare 
the time invested in the translation against the quality of the final version, while Shih (2006) uses interviews with 26 non-literary translators in Taiwan to better understand how they conducted self-revisions.

Siponkoski (2014) is one of the few researchers who has explored the revision of literary texts. His dissertation studies the interplay between translators and editors in the revision process of four contemporary Finnish translations of Shakespeare’s tragedies. The manuscripts of the edited translations with handwritten notes by two copyeditors and a consultant were analysed to study the negotiation process. He concluded that established translators have more power, which means that the negotiation is influenced by the status of the translator. Hemmungs Wirtén (1998) had access to the translator drafts, the edited drafts and the final versions of two novels published by Harlequin Stockholm and discusses omissions, substitutions and mistakes (often indicating carelessness and haste). Her analysis shows radical manipulations in the revision process. She also shows how the editor (in Harlequin's case) always supersedes the translator and "exerts a powerful influence over this process" (p. 153).

Mossop’s (2007a, p. 125) taxonomy of revision parameters is an important resource for studies about revision. Mossop classifies problems into four groups, each of which includes various parameters: problems of meaning transfer (accuracy and completeness), problems of content (logic, facts), problems of language and style (smoothness, tailoring, sub-language, idiom, mechanics) and problems of physical presentation (layout, typography, organisation). This taxonomy was applied by McDonough Dolmaya (2015), who used it to classify changes in the revision of a sample of Wikipedia pages.

Concerning revisions by a second translator, according to Mossop (2011-2016, p. 137), 'the degree of revision effort may depend on the importance of the job', but it 
may also depend on the reviser's confidence in the translator: 'if the translator is known to have extensive experience in the field, the reviser may simply check the nonspecialized aspects of the translation, or perhaps place a question mark or Comment box on specialized passages that seem odd' (ibid., p. 136). This is related to efficacy, as checking a translation word by word significantly increases the time spent on the revision.

Efficacy is another important issue in previous research on revisions. It also concerns the kind of changes revisers should (or should not) suggest. According to Mossop (2011-2016, p. 138), 'unnecessary changes are the main feature of poor revision', while Parra Galiano (2007) recommends that revisers make minimal changes to the translation to save time.

Regarding efficacy, Parra Galiano (2007), based on previous research by Horguelin (1985), Horguelin and Brunette (1998), Hosington and Horguelin (1980) and Mossop (2001), suggests first reading the translation as if it were an original text (without checking against the original) and then studying the viability of revising the translation considering the number of errors identified and the time and budget available. If an unacceptable number of errors is identified, the translation may be returned to the translator or assigned to another translator.

\section{Method}

The study presented in this article is part of a broader research project that seeks to explore and document the production of translations by a digital publishing initiative (¡Hjckrrh!). For this purpose, it closely followed the process of publishing two e-books, from the negotiations of translation rights to the uploading of the epubs to the online platforms for their commercialisation. Given the objectives of this article, that is, to describe the revision by translators, the negotiation of changes during the revision 
process and the interaction between actors in an informal, non-profit and digital publishing initiative, an ethnography-inspired qualitative method was chosen. It was also inspired by Buzélin’s (2007) idea of a sociology of translation, which focuses ‘on the production end rather than the reception end' (2007, p. 135). Participant observation was conducted during the making of two e-books. The Principal Investigator (PI) was the translator of an e-book during the pilot project and was involved in the revision of a second e-book, which allowed her to have access to privileged data.

Data for this project were collected from multiple sources.

a) Self-reports from the participants gathered from:

i. $\quad 16$ in-depth interviews, including the 3 founding members of ¡Hjckrrh!, 9 translators that had translated literary works published by ¡Hjckrrh! (including the PI, who participated as a translator), the cover designer, 2 revisers and a proofreader; ${ }^{3}$ and

ii. reflective diaries written by the 2 researchers, based on field notes, and diaries written by the agents involved in the making of 2 of the works published by ¡Hjckrrh!.

b) Internal documentation of the publishing initiative concerning the two translations that were the object of study, ${ }^{4}$ such as e-mails exchanged by the participants to document the interaction between the different agents.

c) Drafts of the two translations and paratexts of the works published by

¡Hjckrrh! including the cover, preface, postface, footnotes, webpage, blog entries and tweets.

3 For the sake of clarity, when referring to participants we distinguish between revisers, who read and suggest changes to a translation draft, often checking it against the original, and proofreaders, who usually read a quasi-final version already converted into an e-book format (epub, mobi).

$4 \quad$ Un paraíso sobre el infierno: tres cuentos de Shanghai by Liu Na'ou, Mu Shiying and Du Heng, and La cabeza by Dorothy Tse. 
During the data analysis process, the data were triangulated to increase the reliability of the findings and to overcome the deficiencies associated with using a single method. In this article, we use information extracted from the various sources, but special consideration is given to interviews, revision drafts and e-mails.

The interviews were informal and semi-structured (see also Marin-Lacarta and Vargas-Urpi, 2018). They were used to collect information about common practices in ¡Hjckrrh! (e.g., concerning translators’ motivations for engaging in the process, translation practices, copyright issues, revision). The information collected in the interviews was used to reduce the possible bias introduced by focusing on the making of two e-books. All informants gave written informed consent. ${ }^{5}$

All the data collected in the project (verbatim transcripts of the interviews, emails, drafts, etc.) were analysed using Atlas.ti, a software program for qualitative data analysis. Atlas.ti allows codes to be assigned to specific excerpts (see Figure 1 for an example), which can then be retrieved easily. For example, the code 'negotiation of changes’ was assigned to excerpts from the transcriptions of interviews and Skype conversations, e-mails and translation drafts that mentioned how the changes suggested during the revision of translations were accepted or rejected. The results in this article show how the various excerpts that were assigned the same code were combined and contrasted to provide a wider description of the object of study.

5 This project was submitted to and approved by the Board of Ethics of Hong Kong Baptist University. 


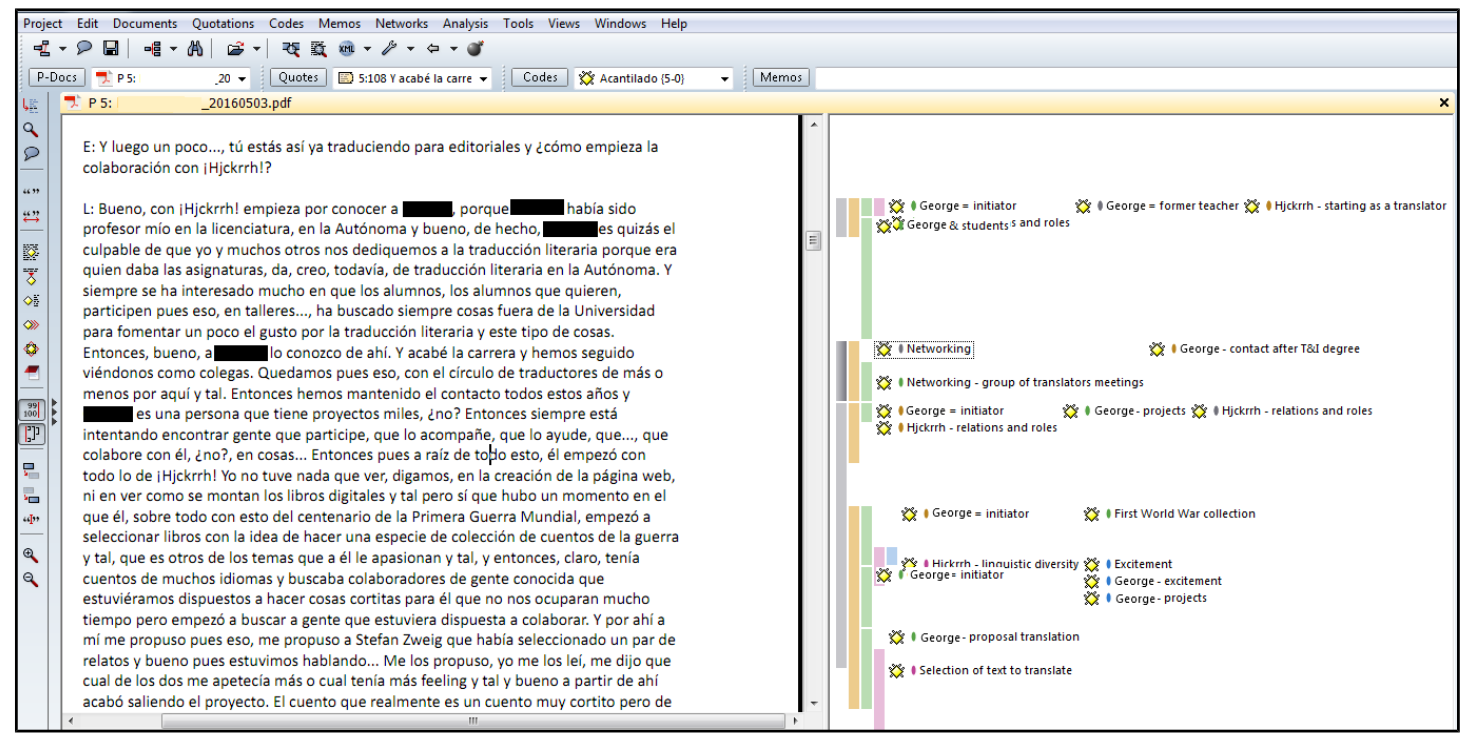

Figure 1. Screenshot of Atlas.ti’s coding interface

\section{4. $\quad$ Results}

There seems to be a general and recurrent workflow in ¡Hjckrrh! concerning the revision of translations that reflects Mossop’s (2007a) characterisation of revision parameters, as may be noted in the following sequence:

a) revision of the translation, checking it against the original, looking for content and transfer problems;

b) revision of the language and style, usually performed by Gerardo ${ }^{6}$, who takes the role of chief editor;

c) negotiation of changes with the translator or between revisers; and d) proofreading and testing by another collaborator (e.g., Cecilia or Sofía)

based on the e-book version and using various e-reader devices.

Each of these phases may include various stages with various actors taking part in them, depending very much on the language involved and the quality of the translation. The first two phases of the protocol sometimes converge into a single phase, as some revisers address content, transfer, language and style problems at the same time. In translations from English into Spanish, Gerardo, who is a professional English$6 \quad$ We have used pseudonyms to anonymise the participants. 
Spanish literary translator and a university lecturer on this subject, often oversees these first phases of the revision process. For example, when asked about the revision process, Felipe only recalled that 'Gerardo did a style revision himself, adding suggestions, highlighting some sentences, and I accepted them all'7

Even in these cases where Gerardo is responsible for the first two phases, there may be various exchanges between the reviser or editor and the translator until a final version is ready for proofreading. Lara recalled that she exchanged 'three or four' versions with Gerardo, who suggested changes using comments in a Word file. As it was a relatively short text, they even discussed the revision over the phone.

Although revisions of content, transfer and style often merge into a single stage, the following sections focus on each of the stages mentioned above.

\subsection{Revision of content and transfer problems in ${ }_{i} H j c k r r h !$}

Despite the Requirements for Translation Services of the International Standard (ISO 17100:2015), revisions based on checking the translation against the original are not frequent in literary translation in the Spanish context. In ¡Hjckrrh!’s revision process, when Simona was asked to revise Amaia's translation, she explicitly asked for more information on the type of 'reading' she was supposed to be doing in an e-mail to Gerardo. This kind of confusion is common, according to Mossop (2011-2016, p. 138), because 'revisers are commonly not given a specific revision brief stating what precisely they should check’.

Gerardo’s answer to Simona was as follows: 'What we need now is a revision from Toury's perspective of adequacy. Your revision will be the first we intend to do, then we will continue with the process' (by e-mail). The reference to Toury's adequacy

7 Excerpts from interviews, e-mails, Skype conversations and translation drafts have been translated from Spanish into English by the authors. 
may have not been very clear, because Simona then insisted: 'I understand that I have to check that the texts reproduce the original content and that, at the same time, the translated version has the adequate options in the target language. Am I right?'

Amaia explained that her previously published translations had never been revised so exhaustively and certainly never checked against the original version. Furthermore, when Amaia was asked to revise La cabeza, she also told Gerardo: 'I will only compare the translation against the original Chinese without commenting on style, which you will do much better than me'.

Cecilia, who had revised some of Gerardo’s translations, explained that when she knew the translator and how they translated, she only read the translated text and marked parts that sounded strange to her. She only checked those parts against the original and might have added a suggestion if she had it; otherwise, she might have only left a comment concerning the fluency of that part, so that the translator could work on another option. This is coherent with Mossop’s (2011-16) assertion that the degree of revision effort also depends on the reviser's confidence in the translator.

The process of content revision and transfer in translations from languages other than English varies depending on many factors, but mainly on the availability of translators for that language combination. In the case of the revision of Viaje a Faremido, translated from Hungarian into Spanish, there were no revisers available for that language combination. Thus, the revisers had to compare the translation with three other versions, in French, English and Esperanto. Juan checked the version in Esperanto and offered the following explanation.

Excerpt 1. Interview with Juan, funding member of ¡Hjckrrh! It is a science fiction story, and the language is not very smooth. Sometimes, Gerardo said, 'Look, I don't understand this', and I looked it up in the Esperanto version and I told him what it said because in Esperanto it was absolutely clear. But 
I don't know if the Esperanto version was faithful to the original or not. I can only say that the Esperanto version was much easier to read than what we had in Spanish. It was fluid, and everything was easy to understand, but in Spanish it was very complex, and I imagine that the Hungarian version is very baroque.

This fear, expressed by Juan, that a translation into a third language may not faithfully render the original and thus may end up distorting the translation under revision was also mentioned by Raul, a Turkish-Spanish translator. He recalled similar experiences when other publishers revised his translations from Turkish based on the English or French versions.

Excerpt 2. Interview with Raul, Turkish-Spanish translator Nobody knows Turkish. Then, there might be a problem, because revisers often know English. So they tell you, 'In the English version, there it says so and so'. And English versions are dreadful. In one specific case, it had nothing to do with the original, and the reviser told me, 'The English version says that'. And what am I supposed to do!? If they use the French version, it is usually better because more people know French. But the French, I don’t know why, they always want to make everything look beautiful, and complex. 'Oh, here it says, "wonderful tableware”, and you've used “cutlery”, why?' Well, because the original says 'cutlery', not ‘wonderful tableware'.

Gerardo, in his role of chief editor, seemed to be aware of the problems of using translations in a third language for revising a text. When Amaia's translation of Un paraíso sobre el infierno had to be revised, he explicitly asked Amaia to look for a Chinese-Spanish translator who could do this revision.

Excerpt 3. E-mail from Gerardo (chief editor) to Amaia Sure, we could revise the text using the English or French versions, but if the whole process is going to be documented and must be used as a standard of practice, then it's better to find someone with a good command of both languages to do the revision.

The kind of revisions or suggestions done in this first stage mostly concern content and 
transfer problems, although language and style problems are also addressed. In $\mathrm{La}$ cabeza, which is approximately 6,000 words long, Amaia's first revision consisted of 208 changes, of which 113 corrected transfer or content problems, 73 concerned language problems and 19 pinpointed presentation items. In Un paraíso sobre el infierno, which is approximately 10,000 words long, Simona's first revision consisted of 52 changes using the track changes option, of which 18 were questions or justifications in comment balloons. The majority concerned content problems and, more specifically, accuracy in the translation of very specific elements (e.g., clothing) of Shanghai in the 1930s. Very few of them addressed language problems (such as changing a preposition or an incorrect word).

\subsection{Language and style revision}

Revision of language and style problems, using Mossop’s terminology, is usually performed by Gerardo. This stage is often merged with the first revision concerning content and transfer problems, as already mentioned, or is partially addressed in that first revision. Amaia intended to limit her changes to content and transfer problems when revising La cabeza, but in the end 73 of her 208 suggested changes concerned language or style.

Gerardo’s revisions were rather exhaustive (172 new changes) and mostly tackled problems of adequacy to the target language, such as changing adverbs for locutions, changing the word order in sentences or using more accurate terms. For instance, he changed doctor to médico in his style revision of La cabeza: both terms are widely used in Spanish, but médico is more accurate when it is used to describe the profession rather than as a form of address. 
Jorge, a Chinese-Spanish translator, also mentioned style revisions in his interview, especially revisions performed by revisers who do not know the language of the original. He talked about his experience with another publishing house.

\section{Excerpt 4. Interview with Jorge, Chinese-Spanish translator} One of the reasons I accepted the translation of (XX) was because they accepted my condition that there would only be minor revisions and I would be able to supervise them all. In other words, if a style reviser wanted to change a sentence, he had to warn me so that I could check that his suggestion reproduced the Chinese original version, because a style reviser cannot know that. Let's say that my commitment and faithfulness to the original text was above any reviser's whim because sometimes, to make it sound nice in Spanish, the resulting text does not say the same as the Chinese.

\subsection{Negotiation of changes with the translator or between revisers}

The negotiation of changes with the translator varied substantially depending on Gerardo’s relationship with the translator. When there was some kind of friendship or familiarity, the discussion and negotiation of changes was done over the phone or Skype, and took place at an early stage, right after Gerardo had finished the language and style revision. Lara, Cecilia and Amaia recalled having gone through their texts with Gerardo and discussing the changes to reach a final version. In Lara's particular case, there were 'two or three' phone conversations to talk about the revisions.

In the case of La cabeza, the first conversation to negotiate changes took place between Amaia (content and transfer reviser) and Gerardo (style reviser). In a recorded conversation via Skype, they went through the text for almost an hour (55 minutes). In most cases, Gerardo asked Amaia to tell him exactly what the original said and then, based on Amaia's explanation, they jointly reached a translation solution for the problematic word or sentence. They discussed changes that concerned accuracy, as in the following excerpt. 
Excerpt 5. Skype conversation between Gerardo and Amaia

G: Did he invite her to watch 'a movie' or 'several movies'? Was it only once?

A: Yes.

G: Then, they watched a movie, ate and watched another movie, right? And it was only one day, right?

A: It's not clear! [referring to the original version]

G: Oh... I think they did this only once. A week before the wedding, they did this for a morning and spent the day at the cinema.

Gerardo’s question addresses a common doubt when translating from Chinese into Spanish and other languages (such as English): the original is ambiguous because of the absence of plural forms in Chinese; thus, the translator, unable to maintain the ambiguity, must decide between the singular or the plural form based on the context (if possible). In fact, discussing problems concerning accuracy seems to be a common practice that is not exclusive to translations revised by checking them against the original. For example, Raul also mentioned having a discussion with Gerardo about certain terms that appeared in his translation from Turkish (Aceitunas con pan). Raul explained that he had to translate the name of an object that was similar to a wooden military trunk used to store oilcans for lamps. In Turkish it was, literally, 'oil trunk', but he was unsure about the name in Spanish. Gerardo suggested calling it a 'box' instead of a trunk, and Raul thought that was a very good option.

However, in the Skype conversation between Gerardo and Amaia, most questions concerned language and style problems. For example, Gerardo asked about the frequent repetition of proper names in the translation, as in Spanish repetitions are avoided and the use of synonyms (e.g., 'the father' instead of 'A Muk') or pronouns (he, him) is preferred. Amaia told him that this kind of repetition was frequent in Chinese but that it should be changed to improve the fluency of the final version. In other cases, style and transfer questions seem to overlap, as in the following excerpt.

Excerpt 6. Skype conversation between Gerardo and Amaia 
G: [The part] about the murders, I don't know if there are gradually more deaths or they kill... I don't know, I mean, that word - maybe we can look for another word - but the word 'murder' to talk to a six-year-old boy... What about: 'They're killing more and more people on the streets'?

A: Yes, that would be good.

(...)

G: And later, I don't know, it’s up to you, but maybe it could say: ‘every day they kill so many people'.

A: No, I would leave it like it is: 'they are murdered'. Because, suddenly, in that last sentence, a more formal register is used.

G: In Chinese, too?

A: Yes. I mean in Chinese.

In excerpt 6, a question concerning the use of two synonyms in Spanish ('asesinar', to murder vs. 'matar', to kill) first addresses a style problem that Amaia agrees to change. However, she rejects Gerardo’s second suggestion and tries to maintain the same register as in the original.

However, performing such a detailed revision requires time, and although the dialogue with the translator or, in this case, the first reviser is appreciated, this is not the most efficient method. Concerning the time spent discussing revisions, Juan offered the following explanation.

Excerpt 7. Interview with Juan, one of ¡Hjckrrh!'s founding members Yes, there is dialogue, but in these two cases I have preferred not to get involved [in that dialogue], because it was a matter of saving time, you know. You revise the text, send it to the author [of the translation] and if he likes the revision, he uses it; otherwise, we don't use it. That was my opinion. If the author says no, I won't go into discussions, because I don't want to start with ‘that sounds horrible and it sounds better like this'. But yes, the idea is that we want to respect that the revisions, whoever performs them, are approved by the translators.

It is perhaps for this reason that translators who did not have a close relationship with Gerardo did not usually engage in live discussions with him about the revisions of their texts. For example, Julia said that they ${ }^{8}$ received the revision, but that there were only 
few minor revisions and they did not need to check it again. Felipe also said that he received the text with some marked fragments and that he accepted all the changes. Jorge received the final revised version of the text and accepted it. When Gerardo sent this final revised version to Jorge, he also briefly explained the main changes that had been done, as noted in excerpt 8 .

\footnotetext{
Excerpt 8. E-mail from Gerardo (chief editor) to Jorge

We have finally completed another step of the process. I am sending you the revised version of the story. We have gone through various revisions and made some changes. Perhaps the title is the most obvious: it may be better to use the same word that is used in the story. We have also reduced the frequency of adverbs ending in 'mente'; this is often an interference when translating, and we have conducted an exhaustive comparison between the translation and the original to adjust some parts that were less clear.

I hope you like the result. I think it looks very good. What I am sending to you are the final proofs. Could you take a look at them and give us the final okay?
}

In the two e-books that were the object of study, the negotiation of changes was mostly done between Gerardo and Amaia, translator of Un paraíso sobre el infierno and reviser of La cabeza. Amaia was Gerardo’s former student and they had a close relationship, while Jorge, the translator of La cabeza, did not have a direct relationship with Gerardo. Furthermore, Amaia took on the role of commissioner of the translation of La cabeza, a fact that may help to clarify why most conversations to negotiate changes were held between her and Gerardo, and not directly with the translator.

\subsection{Proofreading and testing}

When a clean version was reached, that is, a version without suggestions, deletions or any other tracked changes, it was converted into e-book format (epub or mobi). Juan, one of ¡Hjckrrh!’s founding members, was responsible for converting the final version into the e-book formats. He explained that when Gerardo's revisions were approved by 
the translator, the word file was sent to him for conversion, and 'then, in principle, there is one last proofreading, which is more "typographical” (...), and it's done on the Ipad, which is also used to check the layout'.

This e-book version was then sent to another collaborator, who was asked to read it and check for any spelling, grammar or language mistakes, but he or she would also comment on any kind of 'strange' sentences. The proofreading overlapped with testing, as it was done when the document had already been converted into e-book format (epub or mobi) and was read on an e-reading device, so that the proofreader could also check that formal aspects concerning the layout were also correct. This stage was especially important when they had to create complex e-books in terms of final layout. For example, Alicia en el país de las maravillas has many illustrations that had to be fixed in specific places and pages so that they did not move or lose their shape if different e-readers were used or a zoom was applied by the reader.

Gerardo usually proofread the final e-pubs. He often asked Sofía, his wife, to read them too, because as an 'outsider' to the profession she might perceive unclear points that other revisers had overlooked. Cecilia was also frequently asked to proofread translations by others because she had a different device, so she could also test that the final version looked correct in her e-reader.

Even at a stage in which a book was only proofread for typos, according to Juan, if someone 'sees something they don't like in terms of style, (...) you still revise it, because you are still in time to do so’. For instance, once the epub file for Un paraíso sobre el infierno was ready, it was sent to Cecilia for the proofreading and testing. She suggested 51 language and style changes in a separate Word file. She suggested changing some verbs or prepositions to better fit the context of the corresponding sentences; for example, in Spanish, the collocation 'con el nombre de’ (literally, 'with 
the name of') was preferred to 'bajo el nombre de' (literally, 'under the name of'). She also suggested changing the order of the words in some sentences and questioned the use of certain words considering the historical context of the production of the original text; for example, the translator used 'ligar' (to hit on) and the proofreader (Cecilia) asked whether this use was not anachronistic for a text originally written in the 1930s.

\subsection{A special case: revisions of La cabeza}

In some cases, deviations from this standard path occurred. In La cabeza, once Amaia and Gerardo had negotiated changes via Skype and agreed on a 'clean' version, it was sent to Inés (Chinese-Spanish translator). Inés had not previously collaborated with ¡Hjckrrh!, but she was involved in the research project as a research assistant, and Amaia suggested sending it to her 'because four eyes see more than two', in Amaia's words. Inés had previously read the original Chinese version before she was asked to engage in the revision process. She started working with the draft that had been negotiated by Amaia and Gerardo, but then decided to compare it with the original, as she recalls in excerpt 9 .

Excerpt 9. Interview with Inés, Chinese-Spanish translator [T]here were things that I didn't remember having read in the original, and that was when I started checking both versions, because I said, 'Hey, Amaia, I think I’m going to check it word by word against the Chinese'. (...) And, then, I also went crazy putting comments and making changes and, indeed, the final version had more than a hundred comments in only eight pages.

Inés’ memory was rather accurate: she made 120 changes using track changes and introduced 95 comments using balloons. Track changes were used mostly for revisions concerning language problems (e.g., postponing the adjective to the noun) and verb tenses. Comment balloons were used to pinpoint omissions or deviations from the original, alternative options in terms of expression or language problems. 
After Inés’ revision, Amaia and Gerardo had a second meeting via Skype to discuss Inés’ suggestions, accepting some of them and rejecting others. This was the version used to make the e-book. It was then sent back to Inés for proofreading and testing. She suggested 18 changes, 4 of them corresponding to the prologue. Some of these changes concerned layout (e.g., missing spaces between Chinese words in the text and the following words in Spanish, words that should be in italics, etc.). Other suggestions concerned the unification of criteria (e.g., 'futbol' vs. 'fútbol'), punctuation and sentence structure. In tune with this, Cecilia commented that 'the more you read (a text), the more mistakes you find. It is as if they reproduce'.

That the making of La cabeza and Un paraíso sobre el infierno was being studied as part of the larger research project may also explain why some parts of their production process deviated from the standard path. Excerpt 3 reflects some of this contamination of the social environment being studied: Gerardo, aware that his practices were being observed and analysed, suggested using what he considered best practices (i.e., bilingual revisers for the content and transfer revision).

\subsection{Perceptions of the revision process}

In general, translators who participated in ¡Hjckrrh! had the impression that their translations underwent a lot of revisions. Furthermore, most of them saw these exhaustive revisions as positive, as Daniel explains in the following excerpt.

Excerpt 10. Interview with Daniel, English/Italian-Spanish translator The text went back and forth between Gerardo and me. I sent him a draft, he read it, made comments, I changed some things; then Cecilia read it, she also suggested changes, I changed it again; then Sofía read it, and she also marked some points that we revised again. The text went back and forth, and it was something very collaborative; you felt accompanied.

Lidia also explained that the translation 'had benefitted from many revisions, and that 
does not often happen'. Lara explicitly said that her translations never underwent such exhaustive revisions, even though in small publishing houses translators may also have some possibility of supervising the revisions of their work. In Lara's experience, in bigger publishing houses, due to the time pressure of commercial deadlines, it was more difficult to supervise the revision process. Felipe shared a similar idea of small publishing houses. Raul, on the contrary, thought that small publishing houses, due to budget constraints, ‘don’t have revisers or they hire revisers who don’t get along with them and they never get in touch with you [for the revision]'. Instead, in Raul's experience, in bigger publishing houses 'the reviser is in touch with the translator and they work together, and it works well'.

Such exhaustive revisions (not only the negotiation of changes), especially if they include checking against the original, require a significant amount of time. Cecilia explained that this was possible in ${ }_{¡} H j$ ckrrh! because there was no time pressure to publish the texts. With other publishing houses, though, spending so much time in the revision process would not be viable: the translator is not paid for the time spent supervising the revisions suggested to their texts.

When Amaia and Inés were asked how long they had spent revising the text, they both exclaimed: 'A long time!' According to the revisers’ diaries, Simone spent 7.5 hours revising Un paraíso sobre el infierno (10,216 words), and Amaia’s first revision of La cabeza (5,637 words in the first draft) took her approximately 11 hours. The important differences in the revising speed might have been related to the complexity of the texts (La cabeza is a surrealistic story), but also to the quality of the translations. Furthermore, to Amaia’s 11 hours of revision, one must add another hour of Skype conversation, Gerardo’s and Inés’ revising hours and another Skype conversation with Gerardo. 


\section{Conclusions}

This article sheds light on a topic that has been little explored to date: revisions in literary translation. It focuses on the revision practices inside a very specific non-profit publishing initiative, and thus the results may not be representative of general editorial practices in literary translation. Even so, the results reflect attitudes and work habits that may be further explored in future studies.

First of all, it is interesting that most translators appreciate the opportunity to supervise the revisions of their translations and that some even explicitly mention this desire to control what is changed, even if this part of work is not usually included in the reimbursement received for a translation. This reflects translators’ sense of responsibility for the quality of translation as a final product. The possibility of discussing changes between the reviser/editor and the translator is also regarded as a fruitful activity: translators are usually eager to engage in lively discussions while jointly looking for the best solution.

Translators also have a positive view of the various revisions of their translations by various revisers before publication. They feel that this process improves their translations. In this respect, revisions are truly perceived as a means to ensure translation quality. In fact, the only drawback to such exhaustive revisions is the significant amount of time they require. This is contrary to what one would perhaps expect. According to Buzelin (2007, p. 142), the world of publishing is often considered to be a field of tension, governed by conflicts and scandals. No such tension has been found in our case study. This is perhaps due to the fact that translators have the final saying in the revision process, and translators are revising the work of translators.

If, according to Mossop (2011-2016, p. 137), the 'degree of revision may depend on the importance of the job’, ¡Hjckrrh!'s revision practices reflect that 'importance’ in 
this assertion is clearly subjective. It is not strictly related to pragmatic factors (e.g., the economic value attached to the translation, or its purpose), but also emotional factors (e.g., the translator's relationship with the editor, or the sense of engagement in the project).

Some of the examples provided by the interviews, revision drafts and Skype conversations reflect that revisions that involve checking the translations against the original are more efficient in terms of identifying content problems and suggesting solutions. On the contrary, when versions in a third language are used, revisers may suggest inadequate solutions or doubt the reliability of the version used for reference.

As for the various phases involved in the revision process, it seems the revision of style and language usually permeates the whole process. When translators revise other translators' work, they seldom focus only on content, transfer or presentation problems. Instead, suggestions regarding language and style are always put forward, even in the last stage of proofreading, when the translation has already been converted into e-book format.

Finally, in terms of approach, this article shows the usefulness of ethnographyinspired sociologies of translation for providing information about how translators interact with other translators in relation to specific work assignments. Thanks to the use of various data collection strategies, translators' opinions were compared with actual practices, increasing the validity of the results. Although access to data can be challenging, it would be interesting to replicate a similar method in future studies of commercial publishing houses and other non-profit literary translation initiatives.

\section{Funding}


This work was supported by the General Research Fund of the University Grants

Committee in Hong Kong: [grant number GRF HKBU 12608815].

\section{References}

Arthern, P. (1983). Judging the quality of revision. Lebende Sprachen, 28(2), 53-57.

Brunette, L., Gagnon, C. \& Hine, J. (2005). The GREVIS project: revise or court calamity. Across Languages and Cultures, 6(1), 29-45.

Buzélin, H. (2007). Translations ‘in the making’. In: M. Wolf \& A. Fukari (Eds.), Constructing a sociology of translation (pp. 135-169). Amsterdam \& Philadelphia: John Benjamins. doi: 10.1075/btl.74.11buz

Hemmungs Wirtén, E. (1998). Global infatuation explorations in transnational publishing and texts (Doctoral dissertation). Section for Sociology of Literature at the Department of Literature, Uppsala University, Uppsala.

Horguelin, P. A. (1985). Pratique de la révision [Revision practice]. Montreal: Linguatech.

Horguelin, P. A., \& Brunette, L. (1998). Pratique de la révision: 3ème édition revue et augmentée [Revision practice: revised and expanded $3^{\text {rd }}$ edition]. Brossard, Québec: Linguatech.

Hosington, B. M., \& Horguelin, P. A. (1980). A practical guide to bilingual revision. Montreal: Linguatech.

Künzli, A. (2006). Translation revision - A study of the performance of ten professional translators revising a technical text. In M. Gotti \& S. Sarcevic (Eds.), Insights into specialized translation (pp. 195-214). Bern \& Frankfurt: Peter Lang.

Marin-Lacarta, M. \& Vargas-Urpi, M. (2018). When the translator does more than translate: a case study of translator roles in a digital publishing initiative. Hermes, 58, forthcoming.

McDonough Dolmaya, J. (2015). Revision history: Translation trends in Wikipedia.

Translation Studies, 8(1), 16-34. doi: 10.1080/14781700.2014.943279

Mossop, B. (2001/2007a). Revising and editing for translators. London and New York: Routledge.

Mossop, B. (2007b). Empirical studies of revision: What we know and need to know. JoSTrans, 8, 5-20.

Mossop, B. (2011-16). Revision. In: Handbook of translation studies online (pp. 135139). Amsterdam \& Philadelphia: John Benjamins. doi: 10.1075/hts.2.rev1 Siponkoski, N. (2014). Translation under negotiation: The textual interplay of translators and editors in contemporary Finnish Shakespeare translation [Doctoral dissertation, Acta Wasaensia 304]. University of Vaasa, Vaasa. 
Parra Galiano, S. (2007). Propuesta metodológica para la revisión de traducciones:

principios generales y parámetros. [Methodological proposal for the revision of translations: General principles and parameters]. TRANS, 11, 197-214.

Shih, C. Y. (2006). Revision from translators' point of view: An interview study. Target, 18(2), 295-312. 